\title{
Which patients with moderate hypoxemia benefit from long-term oxygen therapy? Ways forward
}

This article was published in the following Dove Press journal:

International Journal of COPD

\author{
Magnus Ekström' \\ Thomas Ringbaek ${ }^{2}$ \\ 'Department of Respiratory Medicine \\ and Allergology, Skåne University \\ Hospital, Lund University, Lund, \\ Sweden; ${ }^{2}$ Respiratory Department, \\ Hvidovre Hospital, Copenhagen, \\ Denmark
}

\begin{abstract}
Long-term oxygen therapy (LTOT) improves prognosis in patients with COPD and chronic severe hypoxemia. The efficacy in moderate hypoxemia (tension of arterial oxygen; on air, 7.4-8.0 kPa) was questioned by a recent large trial. We reviewed the evidence to date (five randomized trials; 1,191 participants, all with COPD). Based on the current evidence, the survival time may be improved in patients with moderate hypoxemia with secondary polycythemia or right-sided heart failure, but not in the absence of these signs. Clinically, LTOT is not indicated in moderate hypoxemia except in the few patients with polycythemia or signs of right-sided heart failure, which may reflect more chronic and severe hypoxemia.
\end{abstract}

Keywords: survival, oxygen therapy, hypoxemia, COPD

\section{Introduction}

Long-term oxygen therapy (LTOT) improved prognosis in patients with COPD and chronic severe hypoxemia in the NOTT and MRC randomized controlled trials (RCTs) conducted in the 1970s $(\mathrm{n}=290) .{ }^{1,2}$ Based on the inclusion criteria of these trials, ${ }^{1,2}$ the established indications for LTOT are chronic severe hypoxemia (tension of arterial oxygen $\left[\mathrm{PaO}_{2}\right]$ on air $\left.\leq 7.3 \mathrm{kPa}\right)$ or moderate hypoxemia $(7.4-8.0 \mathrm{kPa})$ with concurrent polycythemia (erythrocyte volume fraction $[E V F]>0.54$ ) or signs of right-sided heart failure or pulmonary hypertension. ${ }^{3}$ Chronicity was defined as the resting daytime hypoxemia at least 3 weeks apart despite optimal therapy of the underlying disease(s) and the patient being in stable clinical condition. ${ }^{2}$

LTOT is given to prolong survival, and published evidence pertains to patients with COPD. ${ }^{4,5}$ A recent Cochrane report found no evidence for benefit from LTOT on breathlessness or health-related quality of life in the absence of severe resting hypoxemia. ${ }^{6}$ Surveys from several countries report that $\sim 15 \%-45 \%$ of the patients on LTOT do not meet the hypoxemia criteria and that many patients on LTOT have moderate hypoxemia. ${ }^{7}$ The effect of LTOT on mortality in moderate hypoxemia has been questioned, ${ }^{4,8}$ most recently by the large Long-Term Oxygen Therapy Trial (LOTT; $n=738) .{ }^{5}$ We aimed to evaluate the effect of LTOT on mortality to inform its clinical usefulness and research priorities in patients with COPD and moderate hypoxemia. We also aimed to identify trial characteristics that could explain the differences in outcomes between studies with focus on the required level and chronicity of hypoxemia.

\section{Methods}

We identified studies fulfilling all the inclusion criteria: RCT design; compared LTOT, defined as oxygen therapy prescribed $\geq 15 \mathrm{~h} /$ day, with air or no LTOT; included 
patients with COPD and moderate hypoxemia; and reported outcome data on mortality. Trials were identified by searching Medline using keywords ("oxygen therapy" or "LTOT"), reference lists of published Cochrane reports, ${ }^{4,6}$ recent clinical guidelines, ${ }^{3}$ and papers in the field ${ }^{5}$ up to May 19, 2017. Abstracts were screened against the eligibility criteria by Magnus Ekström. Data from full-text articles were extracted and cross-validated by both authors independently. Extracted data included study design, publication year, eligibility criteria, number of participants with moderate hypoxemia, study interventions, blinding, and findings. Disagreements were solved through consensus, and data were tabulated. Focus was on relating the difference in outcomes between studies to eligibility criteria including the required level and chronicity of hypoxemia. Meta-analysis was not performed due to heterogeneity in study designs and insufficient reported outcome data for people with moderate hypoxemia.

\section{Results}

After screening 9,075 records, a total of five $\mathrm{RCTs}^{1,2,5,8,10}$ (1,191 participants) of the efficacy of LTOT on mortality were included (Table 1). All participants had COPD, and the majority were men. Current smokers were included in the MRC trial (52\% in the oxygen group and 33\% in the control group) and in the NOTT (38\% smoked regularly at the time of the study), whereas smoking was a contraindication for participation in the other three trials. None of the trials were blinded (Table 1). Moderate resting hypoxemia was defined as a $\mathrm{PaO}_{2}$ (air) $\geq 7.4 \mathrm{kPa}$ in all studies except LOTT where it was defined as a saturation using pulse oximetry $\left(\mathrm{SpO}_{2}\right)$ of $89 \%-93 \%$.

The number of participants with moderate hypoxemia was not separately reported in the NOTT and MRC trials. Moderate resting hypoxemia was present in all participants in the studies by Gorecka et $\mathrm{al}^{8}(\mathrm{n}=135)$ and Haidl et $\mathrm{al}^{10}(\mathrm{n}=28)$ and 419 of 738 participants (57\%) in the LOTT.

LTOT prescribed $24 \mathrm{~h}$ /day decreased the mortality rate compared with oxygen only during the night in NOTT, and the effect was consistent between participants with $\mathrm{PaO}_{2}$ (air) above or below $6.9 \mathrm{kPa}$. More specific outcomes for the group with moderate hypoxemia were not reported in NOTT or MRC. In the subsequent three trials ${ }^{1,2,5}(\mathrm{n}=582)$, there was no between-group difference in the mortality rate (Table 1).

In terms of eligibility criteria, participants were required to have stable hypoxemia across a defined time period in the NOTT (1 week), MRC (3 weeks), and in the trial by Gorecka et al (3 weeks). In the pilot study of Haidl et al, ${ }^{10}$ patients were included in the trial during a COPD exacerbation. In the

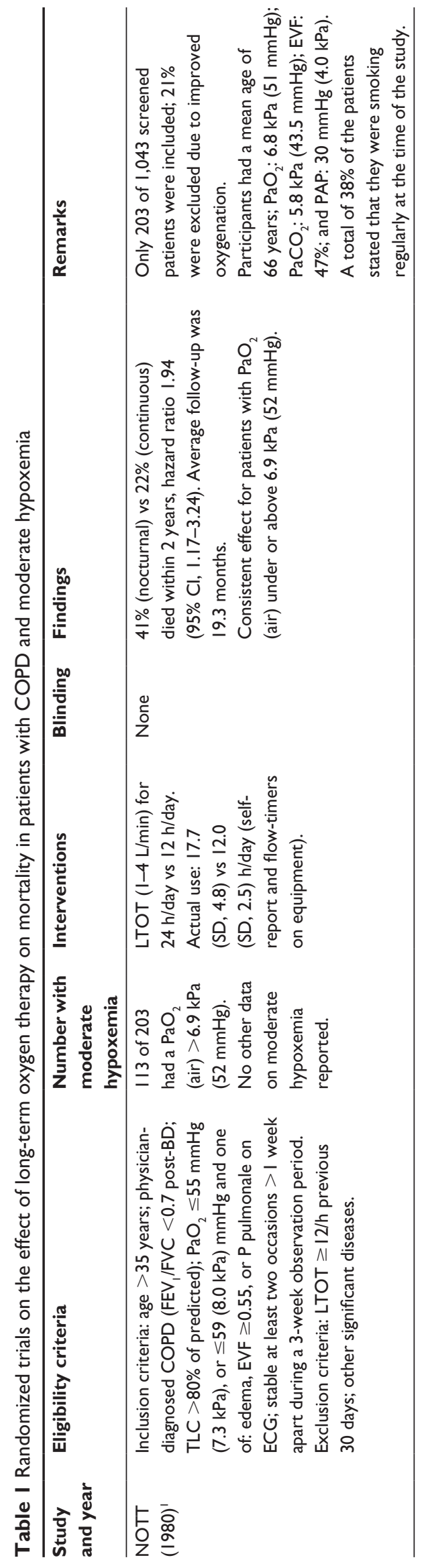




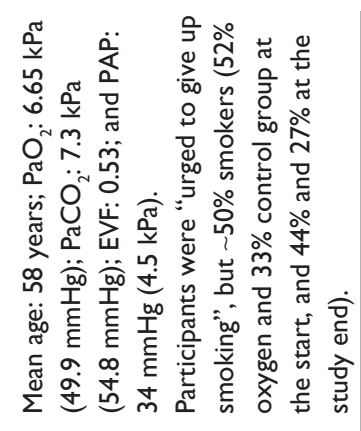

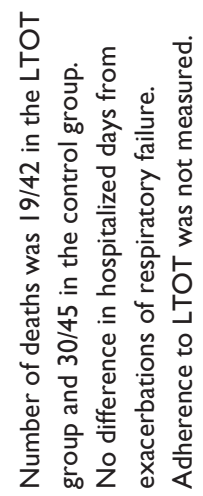

$\stackrel{0}{5}$

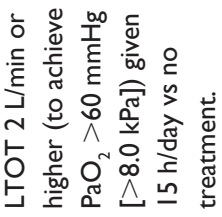

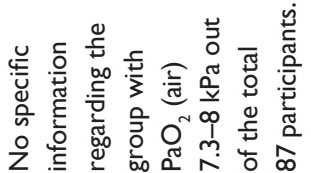

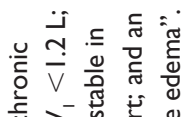

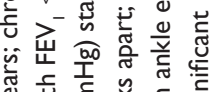

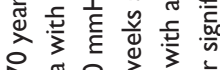

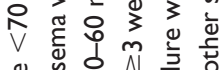

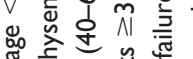

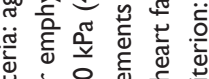

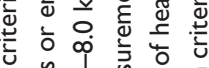

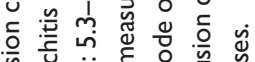

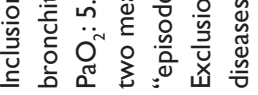

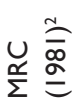

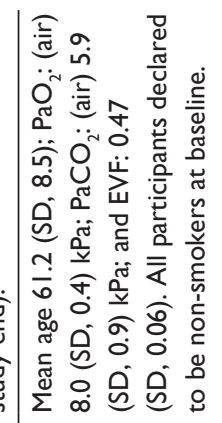

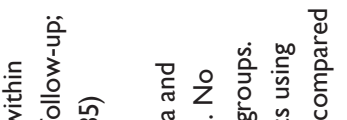

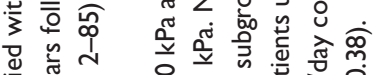

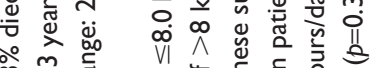

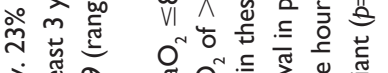

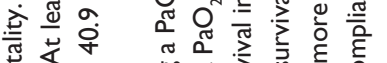

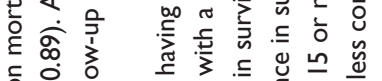

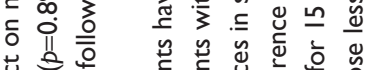

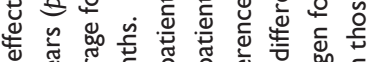

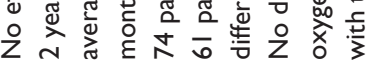

号

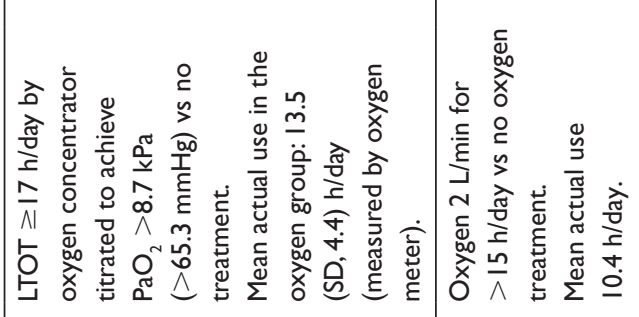

$\hat{m}$

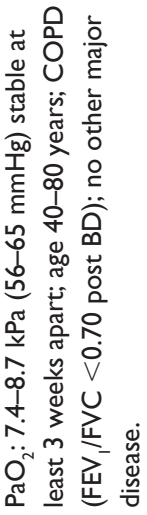

竞

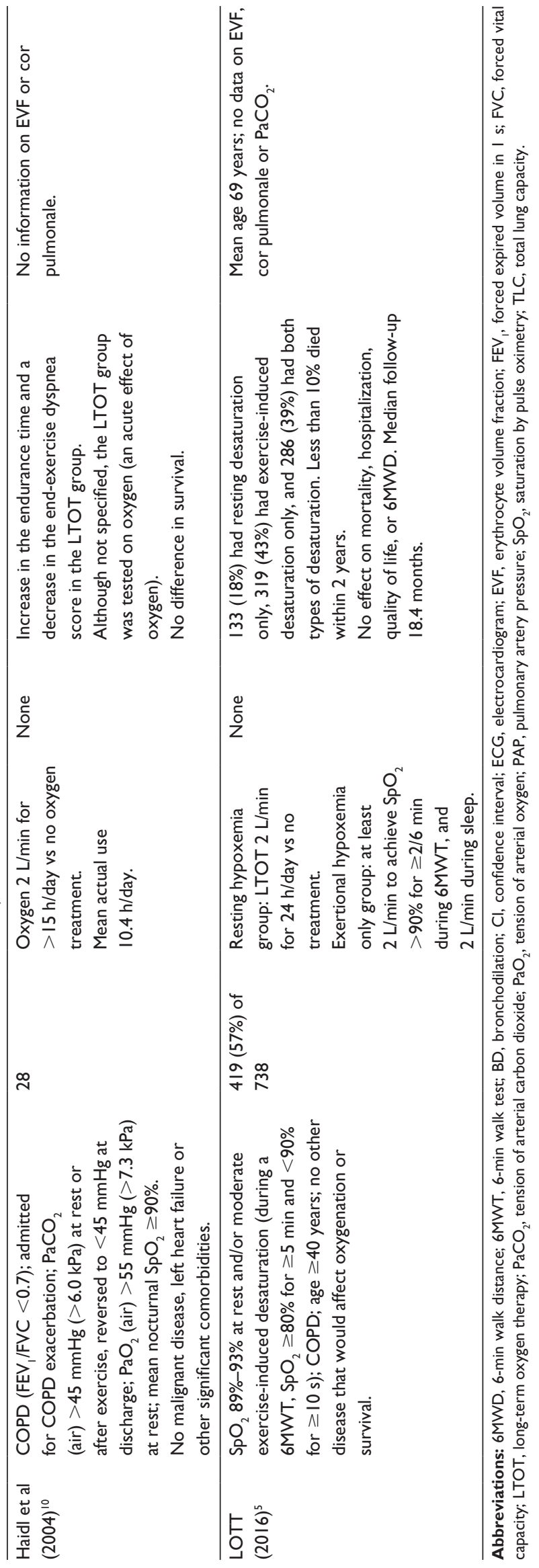


LOTT, hypoxemia was assessed using pulse oximetry, not blood gases, and patients who had been hospitalized because of a COPD exacerbation or other acute conditions 30 days prior to screening were excluded. Signs of chronicity or more severe hypoxemia were required in people with moderate hypoxemia in the NOTT (edema, hematocrit $\geq 55 \%$, or $\mathrm{P}$ pulmonale on ECG) and MRC trial (at least one episode of heart failure with ankle edema). Such signs of chronicity were not required in the three subsequent trials including the LOTT.

\section{Discussion}

The current evidence supports that LTOT does not improve the prognosis in patients with COPD and moderate hypoxemia except in the few patients with polycythemia or signs of right-sided heart failure.

When considering the effect of LTOT, central factors are level of hypoxemia and its chronicity. The only trials showing a survival benefit of LTOT were the original NOTT and MRC trials that included patients with severe hypoxemia and patients with moderate hypoxemia together with signs of hypoxemia-related complications. ${ }^{1,2}$

It is also known that hypoxemia often is transient. About $30 \%-50 \%$ of hypoxemic patients initially classified as clinically stable did not fulfill the hypoxemia criteria at re-evaluation at 2-3 months. ${ }^{1,9}$ Levi-Valensi et al ${ }^{9}$ demonstrated that $20 \%$ of those who still met the hypoxemia criteria at 1 month were no longer hypoxemic after 3 months. Similar improvement may be seen in patients with moderate hypoxemia. After a 1-3 week re-evaluation period in the NOTT, only 203 (19\%) of 1,043 screened patients were included, and $21 \%$ of exclusions were due to improved blood gases. ${ }^{1}$ The re-evaluation of blood gases and, in patients with moderate hypoxemia, the requirement of signs of possible hypoxemia complications is likely to have restricted inclusion in the NOTT and MRC study mainly to patients with underlying chronic and severe hypoxemia. The lack of such measures, except in the study by Gorecka et al, ${ }^{8}$ could partly explain the lack of effectiveness of LTOT in more recent trials that did not assess the chronicity of hypoxemia and highlight the importance of re-evaluating hypoxemia in clinical practice. ${ }^{5,10}$

Compared with patients in the NOTT and MRC trial, patients starting LTOT are now older and have more comorbidities, ${ }^{11,12}$ as well as improved treatment of COPD and comorbid conditions such as cardiovascular diseases. In light of this and the reviewed evidence to date, we propose that the current hypoxemia criteria of LTOT should be
Table 2 Effect of LTOT in relation to level of hypoxemia and signs of chronicity

\begin{tabular}{lll}
\hline Hypoxemia level & $\begin{array}{l}\text { With signs of } \\
\text { chronicity }\end{array}$ & $\begin{array}{l}\text { Without signs of } \\
\text { chronicity }\end{array}$ \\
\hline $\begin{array}{l}\text { Severe hypoxemia } \\
\left(\mathrm{PaO}_{2} \leq 7.3 \mathrm{kPa}\right)\end{array}$ & LTOT indicated & LTOT; trial $^{\mathrm{a}}$ \\
$\begin{array}{l}\text { Moderate hypoxemia } \\
\left(\mathrm{PaO}_{2} 7.4-8.0 \mathrm{kPa}\right)\end{array}$ & Unclear; trial & LTOT not indicated \\
\hline
\end{tabular}

Notes: Signs of chronicity include secondary polycythemia (EVF $>0.54$ ) or signs of right-sided heart failure or pulmonary hypertension. aLTOT may be provided based on the NOTT' and $\mathrm{MRC}^{2}$ study. We suggest the need for an efficacy trial of LTOT in people with $\mathrm{PaO}_{2}>7.0 \mathrm{kPa}$ without signs of chronicity. ${ }^{\text {b Usefulness of LTOT was }}$ supported by NOTT but is questionable in light of the LOTT; an efficacy trial is needed.

Abbreviations: EVF, erythrocyte volume fraction; LTOT, long-term oxygen therapy; LOTT, Long-Term Oxygen Therapy Trial; $\mathrm{PaO}_{2}$, tension of arterial oxygen.

challenged (Table 2). Trials are needed on the efficacy of LTOT in people with: 1) moderate hypoxemia and signs of chronicity, based on the LOTT; ${ }^{1}$ 2) $\mathrm{PaO}_{2}$ 7.0-7.4 kPa, given the recent negative data in moderate hypoxemia, especially if trials in moderate hypoxemia and signs of chronicity turn out to be negative. Trials should establish and require chronicity of the hypoxemia and, in addition to survival, evaluate effects on hospitalizations, breathlessness, and quality of life where data are insufficient or lacking in severe hypoxemia. ${ }^{1,2}$

\section{Conclusion}

There is no evidence that LTOT has beneficial effect on patients with moderate hypoxemia without signs of chronic hypoxemia, and more studies are needed to establish solid evidence-based criteria for LTOT.

\section{Author contributions}

$\mathrm{ME}$ contributed to concept and design. Both authors contributed toward data analysis, drafting and critically revising the paper, gave final approval of the version to be published, and agree to be accountable for all aspects of the work.

\section{Disclosure}

The authors report no conflicts of interest in this work.

\section{References}

1. Nocturnal Oxygen Therapy Trial Group. Continuous or nocturnal oxygen therapy in hypoxemic chronic obstructive lung disease: a clinical trial. Ann Intern Med. 1980;93(3):391-398.

2. Medical Research Council Working Party. Long term domiciliary oxygen therapy in chronic hypoxic cor pulmonale complicating chronic bronchitis and emphysema. Lancet. 1981;1(8222):681-686.

3. Hardinge M, Annandale J, Bourne S, et al; British Thoracic Society Home Oxygen Guideline Development Group; British Thoracic Society Standards of Care Committee. British Thoracic Society guidelines for home oxygen use in adults. Thorax. 2015;70(suppl 1):i1-i43.

4. Cranston JM, Crockett AJ, Moss JR, Alpers JH. Domiciliary oxygen for chronic obstructive pulmonary disease. Cochrane Database Syst Rev. 2005;4:CD001744. 
5. The Long-Term Oxygen Treatment Trial Research Group; Albert RK, $\mathrm{Au} \mathrm{DH}$, et al. A randomized trial of long-term oxygen for COPD with moderate desaturation. N Engl J Med. 2016;375(17):1617-1627.

6. Ekström M, Ahmadi Z, Bornefalk-Hermansson A, Abernethy A, Currow D. Oxygen for breathlessness in patients with chronic obstructive pulmonary disease who do not qualify for home oxygen therapy. Cochrane Database Syst Rev. 2016;11:CD006429.

7. Pepin JL, Barjhoux CE, Deschaux C, Brambilla C. Long-term oxygen therapy at home. Compliance with medical prescription and effective use of therapy. ANTADIR Working Group on Oxygen Therapy. Association Nationale de Traitement a Domicile des Insuffisants Respiratories. Chest. 1996;109(5):1144-1150.

8. Gorecka D, Gorzelak K, Sliwinski P, Tobiasz M, Zielinski J. Effect of long-term oxygen therapy on survival in patients with chronic obstructive pulmonary disease with moderate hypoxaemia. Thorax. 1997;52(8): 674-679.
9. Levi-Valensi P, Weitzenblum E, Pedinielli J-L, Racineux J-L, Duwoos H. Three-month follow-up of arterial blood gas determinations in candidates for long-term oxygen therapy. Am Rev Respir Dis. 1986;133(4): $547-551$.

10. Haidl P, Clement C, Wiese C, Dellweg D, Kohler D. Long-term oxygen therapy stops the natural decline of endurance in COPD patients with reversible hypercapnia. Respiration. 2004;71(4):342-347.

11. Crockett AJ, Cranston JM, Moss JR, Alpers JH. Survival on long-term oxygen therapy in chronic airflow limitation: from evidence to outcomes in the routine clinical setting. Intern Med J. 2001;31(8):448-454.

12. Ahmadi Z, Sundh J, Bornefalk-Hermansson A, Ekström M. Long-term oxygen therapy 24 vs $15 \mathrm{~h} /$ day and mortality in chronic obstructive pulmonary disease. PLoS One. 2016;11(9):e0163293.

International Journal of COPD

\section{Publish your work in this journal}

The International Journal of COPD is an international, peer-reviewed journal of therapeutics and pharmacology focusing on concise rapid reporting of clinical studies and reviews in COPD. Special focus is given to the pathophysiological processes underlying the disease, intervention programs, patient focused education, and self management protocols.

\section{Dovepress}

This journal is indexed on PubMed Central, MedLine and CAS. The manuscript management system is completely online and includes a very quick and fair peer-review system, which is all easy to use. Visit http://www.dovepress.com/testimonials.php to read real quotes from published authors.

Submit your manuscript here: http://www.dovepress.com/international-journal-of-chronic-obstructive-pulmonary-disease-journal 